IP Periodica Polytechnica Civil Engineering

60(2), pp. 217 221 2016

DOI: $10.3311 /$ PPci.7867

Creative Commons Attribution (1)

RESEARCH ARTICLE

\section{In-Plane Behavior of Masonry Infill Wall Considering Out-of-Plane Loading}

\author{
Jingchang Kong, Changhai Zhai, Xiaomin Wang
}

Received 10-12-2014, revised 15-09-2015, accepted 17-12-2015

\begin{abstract}
The in-plane seismic performance of framed masonry wall has been studied by many researchers all over the world, whereas structures subject not only in-plane load but also outof-plane load simultaneously in actual events. This paper utilizes three dimensional nonlinear finite element analysis techniques to investigate the effect of out-of-plane load on the inplane seismic behavior of reinforced concrete $(R C)$ framed masonry wall. The analytical results indicate that the pre-applied out-of-plane loads alter the in-plane failure mode and reduce the in-plane strength of the masonry infilled RC frame. When the out-of-plane load is small enough, masonry wall fails in terms of in-plane strut mode. With the increase of the out-of-plane load, failure mode under in-plane load tends to become arching failure mode.
\end{abstract}

\section{Keywords}

Framed masonry wall $\cdot$ out-of-plane load $\cdot$ in-plane performance failure mode

\section{Jingchang Kong}

School of Civil Engineering, Harbin Institute of Technology, Huanghe Road 73, Harbin, China

e-mail: kjch8811@126.com

\section{Changhai Zhai}

School of Civil Engineering, Harbin Institute of Technology, Huanghe Road 73, Harbin, China

e-mail: zch-hit@hit.edu.cn

\section{Xiaomin Wang}

School of Civil Engineering, Harbin Institute of Technology, Huanghe Road 73, Harbin, China

\section{Introduction}

Masonry walls are used widely in $\mathrm{RC}$ frame structures for their flexibility in layout and economic. Reports on the failure of infilled RC frame structures observed under devastating earthquakes occurred in various regions of the world (such as Chi-Chi in 1999, Kocaeli in 1999, Central Peru in 2007, and Sichuan China in 2008) revealed that ignoring the infill effects in structural analyses may result in significant underestimation of the effects induced by the expected seismic shakings. In-plane failure and out-of-plane failure are the two main failure modes. The in-plane seismic performance has been studied by many researchers all over the world, whereas limited studies have considered the effect of the loadings in the out-of-plane direction that often occurs in the realistic events [1]. Angel [2] and Flanagan [3] are the rare examples which researched the bidirectional behavior of infilled frame. The crack patterns of in-plane and out-of-plane directions are quite similar as the ' $\mathrm{X}$ ' style, which can influence each other [2]. The interaction between in-plane and out-of-plane loading is often ignored due to difficulties in both experiments and theoretical modelling.

Many researchers utilized the finite element technique to study the in-plane behavior of masonry infilled frame structures, such as Liauw and Kwan [4], Lotfi and Shing [5, 6], Lourenco [7], Lourenco and Rots [8],9], Haris and Hortobágyi [10]. Seah [11] developed a two-dimensional FE model for analysis of infill-frames under in-plane loading. Lotfi and Shing [5, 6], Mehrabi [12], and Stavridis and Shing [13] proposed and developed a masonry material model and an interface finite element. The existing models are applicable to either in-plane or out-ofplane loading, whereas in actual earthquakes they are applied at the same time.

In this paper, on the platform of ABAQUS software, the three dimensional separate finite element model with damageplasticity material models and the surface-based contact cohesive interaction model, which can simulate the out-of-plane and in-plane behavior of the framed masonry walls [14], is used to investigate the effect of the prior out-of-plane load on the inplane behavior of masonry infilled RC frame. 


\section{Finite Element Modelling Program}

\subsection{Design details of the model}

Angel [2] conducted a series of experiments to investigate out-of-plane strength of various unreinforced masonry infill panels. Here specimen 1 is adopted to be the prototype structure for the numerical models. The dimensions and reinforcement details for the frame are shown in Fig. 11 Some material properties for concrete, masonry and steel are given in Table 1.

Tab. 1. Material property (MPa)

\begin{tabular}{|c|c|c|}
\hline Material & Property & Value \\
\hline \multirow{3}{*}{ Concrete of frame } & Compressive strength & 55 \\
\hline & Elastic modulus & 28000 \\
\hline & Tensile strength & 2.05 \\
\hline \multirow{3}{*}{ Concrete of base } & Compressive strength & 27.5 \\
\hline & Elastic modulus & 20000 \\
\hline & Tensile strength & 2.05 \\
\hline \multirow{3}{*}{ Masonry } & Compressive strength & 11.5 \\
\hline & Elastic modulus & 7800 \\
\hline & Tensile strength & 0.3 \\
\hline \multirow{4}{*}{$\begin{array}{l}\text { \#3 } \\
\text { \#4 } \\
\text { \#5 } \\
\# 7\end{array}$} & Yield strength & 452 \\
\hline & Yield strength & 457 \\
\hline & Yield strength & 488 \\
\hline & Yield strength & 457 \\
\hline
\end{tabular}

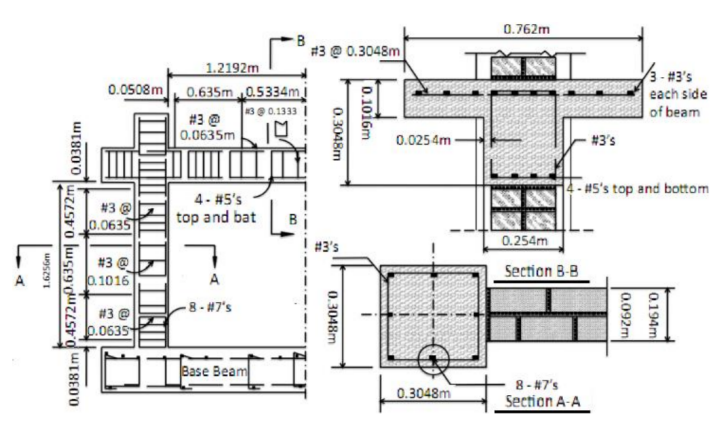

Fig. 1. Dimensions and reinforcement details of the $\mathrm{RC}$ frame

\subsection{Finite element model}

The masonry block is expanded with half layer of the bounding mortar, and the interaction of different expanded blocks is simulated by the surface-based adhesive contact model. Expanded block is defined as combination block. The concrete and combination block are modelled with linear 8-node, 3 dimensional solid element. The reduced integration technique with "average strain" kinematics split method is employed. The reinforcement is modeled with 2-node 3 dimensional truss elements, and steel bars are "embedded" to the concrete element. Progressive refinement of meshing size is conduced to obtain convergent analysis results.

\subsection{Material Modelling}

The constitutive relation adopted for the combination block is the one proposed by Angel [2] as the formula 1and 2 .

$$
\begin{aligned}
& \sigma(\varepsilon)= \\
& \frac{27 f_{m}\left(250 \varepsilon_{c r}-1\right)}{4 \varepsilon_{c r}^{3}} \varepsilon^{3}+\frac{27 f_{m}\left(1-333 \varepsilon_{c r}\right)}{4 \varepsilon_{c r}^{2}} \varepsilon^{2}+750 f_{m} \varepsilon
\end{aligned}
$$

$$
\varepsilon_{c r}=1.6 \varepsilon_{\max }
$$

Where, $\sigma$ and $\varepsilon$ are the stress and strain, respectively. $f_{m}$ is the compressive strength of the masonry, and $\varepsilon_{\max }$ are the crack and maximum strains respectively.

The constitutive of the concrete provided by Chinese code is adopted [15]. The ideal elastic-plastic model is chose as the stress-strain relationship of the steels. The material model adopted for concrete and combination block is the damageplasticity model for quasi-brittle material which has been implemented in ABAQUS [14].

\subsection{Contact property}

The adopted interaction model between different blocks is the surface-based cohesive contact model. The crack between blocks can be modelled by the definition of the tension strength and the soften behavior. The hard contact model is defined for the compression between blocks. The two kind of shear model are the cohesive model and friction model. Surfacedbased cohesive contact model includes three parts: the linear elastic traction-separation behavior, damage initiation criterion and damage evolution criterion [14].

\subsection{Verification of the FE method}

The model was compared separately for in-plane and out-ofplane responses as the behavior in the two orthogonal directions have been widely studied. The validation of the modelling technique on the out-of-plane behavior of masonry infill wall can be found in Zhai et al. [16]. The in-plane verification was presented in Kong [17]. It is indicated that the present model can be used confidently to predict the out-of-plane and in-plane behavior of the structure including the capacity, stiffness and failure mode.

\subsection{Loading patterns for numerical test models}

Based on the presented physics structure and the finite element modelling method, five different numerical tests, as shown in Table 2 are conducted to investigate the effect of the prior out-of-plane load on the in-plane behavior of masonry infilled $\mathrm{RC}$ frame. The geometrical data and the material parameters applied in the FE tests can be found in Fig. 1 and Table 1. In each analysis, boundary condition is setup as same as the experimental specimen [2]. The base beam is fixed. The interface between infill wall and RC frame, as well as the interface between different masonry blocks are simulated through surface-based contact pairs [14].

All structures components are first loaded with design gravity loadings. Vertical load, $2411.5 \mathrm{kPa}$, is then applied on the top of each column of all the models and maintained constant throughout the analysis to simulate vertical force from the upper stories. In the following step the infill wall is loaded with monotonically increasing out-of-plane pressure up to a constant value. And the corresponding out-of-plane displacement at the centre 
of the wall is also shown in Table 2. In the final step nonlinear pushover analysis is performed for each model in the in-plane direction with displacement controlled loading. The monotonically increasing displacement controlled load is applied on the left end of the RC beam. It is noted that the out-of-plane pressure are maintained constant through the whole in-plane loading.

As presented in Table 2, Model 1 is the reference model, which suffers the in-plane loading without pre-applied out-ofplane pressure. The difference between the models is the magnitude of the imposed out-of-plane pressure prior to the in-plane loading.

Tab. 2. Out-of-plane load for each model

\begin{tabular}{lcc}
\hline Model & $\begin{array}{c}\text { Out-of-plane } \\
\text { load }(\mathrm{kPa})\end{array}$ & $\begin{array}{c}\text { Corresponding } \\
\text { displacement }(\mathrm{mm})\end{array}$ \\
\hline Model 1 & 0 & 0 \\
\hline Model 2 & 15 & 4.5 \\
\hline Model 3 & 20 & 7.5 \\
\hline Model 4 & 25 & 13.1 \\
\hline Model 5 & 30 & 24.3
\end{tabular}

\section{Analytical result}

\subsection{Strength and stiffness}

The in-plane load and displacement bearing capacity of each model is shown in Table 3. The in-plane displacement and load resistance is significantly reduced. The last column is the displacement at the center of the wall in the out-of-plane direction. It shows the increase of the initial out-of-plane displacement as shown in Table 3 . This increase is attributed to the effect caused by the in-plane loading.

The relationship curves of in-plane load and displacement for all the models are plot in Fig. 2. It is obvious that all the models' initial stiffness is almost as same as the reference model, Model 1. The largest difference between models is the peak in-plane load and the ultimate in-plane displacement. The out-of-plane deformation prevents the maximum in-plane load-carrying capacity of infill wall from developing fully. The cycle points in the figure represent the infill panels' collapse moment. The curve of the bare frame is presented in the figure too. After the masonry infill collapses, the in-plane load is carried only by RC frame. Fig. 3 shows the relationship between in-plane load and the out-of-plane displacement. It shows the effect explaining the reason for the increasing of out-of-plane displacement. One can see the fact that the in-plane capacity of Model 2 5 dropped when the out-of-plane displacement reaches 50-60 mm.

\subsection{Failure pattern}

The failure patterns of all the analysed structures are shown in Fig. 4, in which the colour from white to black expresses the value of equivalent plastic volume strain (PEEQ). PEEQ is a scalar, which is a measurement of plastic deformation of material. For Model 1, the compressive equivalent plastic strain field
Tab. 3. Load and displacement bearing capacity of models

\begin{tabular}{lccc}
\hline Model & $\begin{array}{c}\text { In-plane } \\
\text { strength }(\mathrm{kN})\end{array}$ & $\begin{array}{c}\text { Ultimate in-plane } \\
\text { displacement }(\mathrm{mm})\end{array}$ & $\begin{array}{c}\text { displacement at the } \\
\text { center of wall }(\mathrm{mm})\end{array}$ \\
\hline Model 1 & 445.1 & 40 & 0.0 \\
\hline Model 2 & 351.2 & 24.5 & 100.0 \\
\hline Model 3 & 295.3 & 14.3 & 75.4 \\
\hline Model 4 & 183.9 & 10.3 & 100.0 \\
\hline Model 5 & 140.1 & 5.7 & 100.0 \\
\hline
\end{tabular}

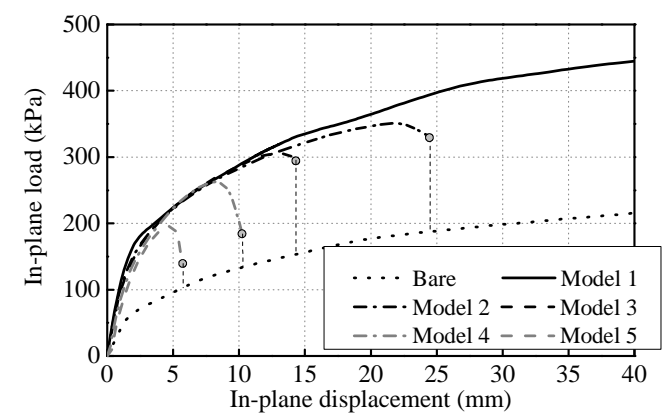

Fig. 2. In-plane load-displacement relationship

is shown in Fig. 4(a). It is seen that the in-plane lateral load is transferred through infill wall from the loading corner to the opposite one. It is agree with the common adoption of diagonal compressive-strut models to account for the effect of infill walls on the strength and stiffness of infilled RC frame.

For Model 2 to Model 5, the predominant failure mechanism shift from in-plane damage mode to out-of-plane collapse mode and hence the failure is depended of the out-of-plane deformations as the pre-applied out-of-plane pressure increases. Thus the load transformation path, diagonal compressive struts, in the infill panels is cut off by the cracks at the centre of the wall. The infill walls drop out before the in-plane maximum capacity is reached. This explains the observation about the decrease of inplane strengths in the last section. So the in-plane capacity of the infill wall cannot be exploited completely with the pre-applied out-of-plane loading. However in the traditional research activities, the effect of loadings in the perpendicular direction on the in-plane capacity is often ignored. The conclusion without considering this effect is not accurate.

\section{Discussion}

\subsection{The interaction relationship between the loads in the} two directions

In-plane strengths for all the models are plot against preapplied out-of-plane pressure in Fig. 5 It can be seen that the in-plane load capacity is significantly reduced with the increase of pre-applied out-of-plane pressure. Calculated from Table 3 . the reductions in in-plane strengths of Model 2 to Model 5 are $21 \%, 34 \%, 59 \%$ and $69 \%$ respectively. In Fig. 5, a trilinear fitting curve is proposed (Eq. 3), where $F_{I}$ is the in-plane load in $\mathrm{kN}$ and $F_{O}$ is the out-of-plane load in $\mathrm{kPa}$.

$F_{I}=486-5.93 F_{O}$ when $F_{O}=(0 \sim 15) \mathrm{kPa}$

$F_{I}=574.2-11.52 F_{O}$ when $F_{O}=(15 \sim 30) \mathrm{kPa}(3)$ 


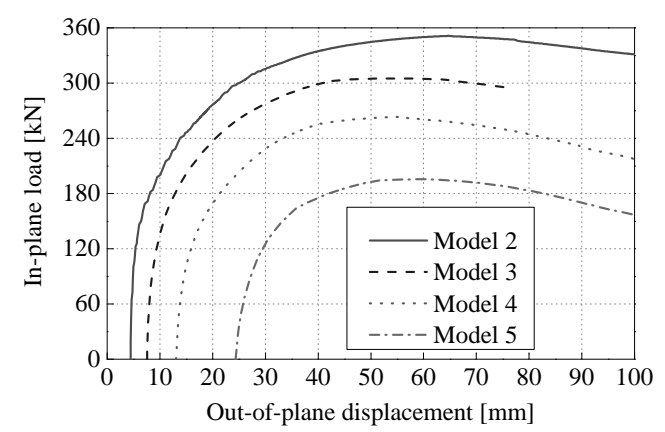

Fig. 3. Relations of in-plane load to out-of-plane displacement

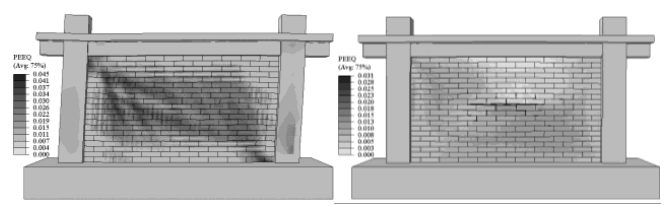

(a) Model 1

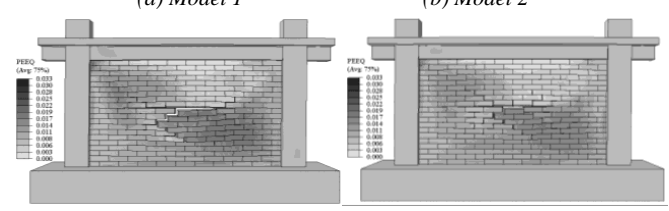

(c) Model $3 \quad$ (d) Model 4

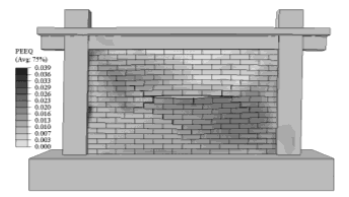

(e) Model 5

Fig. 4. Deformation and strain distribution for models

$$
F_{I}=1838.1-53.90 F_{O} \text { when } F_{O}=(30 \sim 34) \mathrm{kPa}
$$

It should be noted that the results presented in Fig. 5 are specific to the configuration, geometry, and material properties of the studied structure and are not intended to serve as a generalized interaction relationship. Nevertheless, it is believed that the presented computational study in this section demonstrates a general framework for including the in-plane and out-of-plane interaction in analyses involving masonry infill walls.

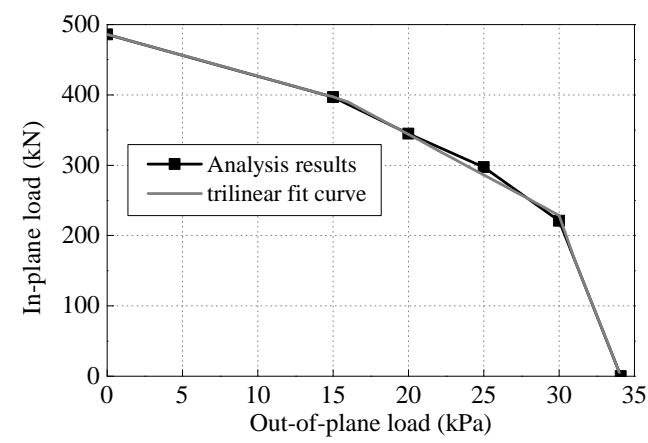

Fig. 5. In-plane strength-out-of-plane load relationship

\subsection{Multi-linear curves for infilled frame}

The in-plane force-deformation behavior of infilled frame structures is rather complex because of significant non-linear activities, including cracking in infill panel even at initial stages of loading leading to separation of infill from frame and some reduction in lateral stiffness [18], subsequent yielding of reinforcement bars and cracking in RC frame members, and eventually failure in masonry infills or RC frames causing changes in strength and stiffness properties throughout force-deformation history. At higher stages of loading, masonry loses all its strength and the strength of the infilled RC frame tends to reach the lateral load capacity of the surrounding bare frame [19].
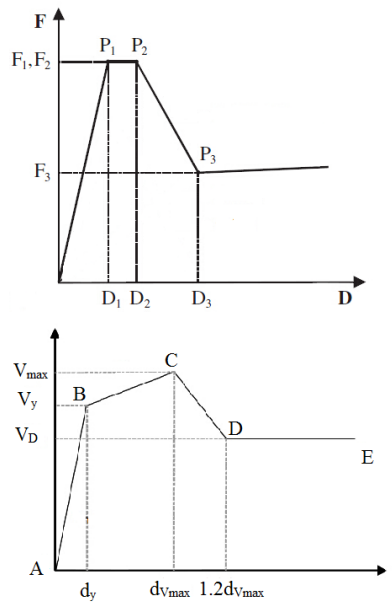

Fig. 6. Examples of multi-linear model
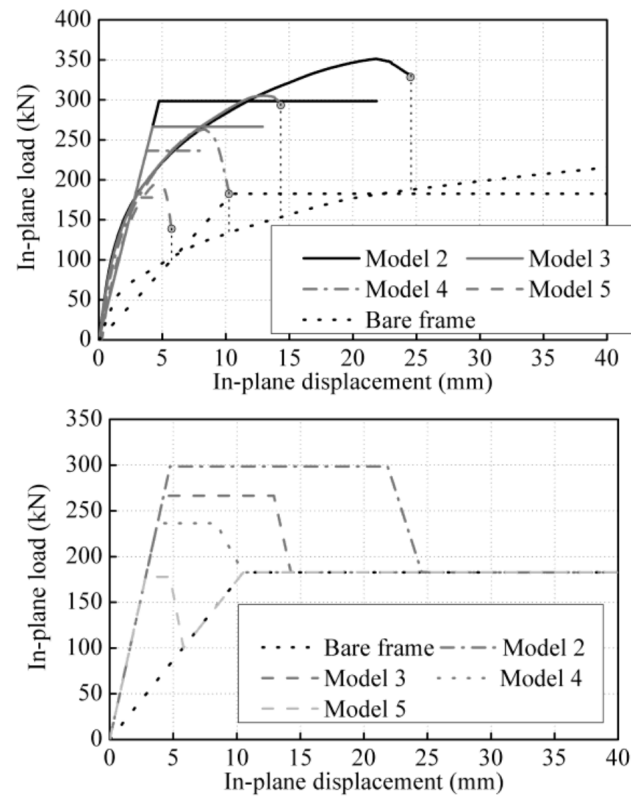

Fig. 7. The multi-linear normalization of the in-plane behavior of Models under various out-of-plane loadings

Similar approaches to model masonry infilled RC frames, such as the force-deformation relationship idealized using three control points connected by four straight lines (Fig. 6), have been adopted by many researchers [18-23]. However, those various macro approaches do not import the influence of the outof-plane loadings, which is unavoidable in the practical events. Hence, in order to accurately capture the seismic behavior of the infilled RC frame, the out-of-plane loadings should be considered in the in-plane force-deformation relationships. The analysed pre-peak curves in Fig. 2 are normalized to multi-linear curves using the equivalent energy method, which are presented 
in Fig. 7. It is obvious that the masonry infill panels share a great part of base shear force from the beginning until to their collapses. As expected, the in-plane force-deformation relationship is remarkably sensitive to the out-of-plane loadings. The decreases in the in-plane strength, the corresponding deflect and the consequence energy dissipation in the earthquake event cannot be ignored in the seismic design and analysis.

\section{Conclusions}

A generic three-dimensional finite element model of $\mathrm{RC}$ framed masonry infill wall has been constructed. A series number of analyses are conducted to study the effect of out-of-plane loading on the in-plane behavior of RC framed masonry panel.

The out-of-plane loading can significantly influence the peak strength in the in-plane loading direction and has no large effect on the initial stiffness. The maximum reduction in strength can be up to $69 \%$.

Under in-plane loading, the pre-existence out-of-plane displacement can be enlarged due to the effect. This causes the failure mode shift from in-plane mode to out-of-plane collapse mode. The crack damage at the centre of the wall cut the inclined strut resistance mechanism off. It is indicated that the traditional compressive strut models cannot reflect the actual damage patterns under loadings in the two directions. Thus it is suggested that the effect of the out-of-plane loading cannot be ignored in the seismic analysis of masonry infilled RC frames to obtain a conservative and accurate conclusion.

The above comments can be considered as a motivation for a further in-depth examination of the seismic response of masonry infilled RC frames. The work in this paper is the preliminary research. Particularly, the future research will be addressing two aspects like a) developing a simplified modelling technology, which can consider the out-of-plane loading, to investigate the global behavior of the multi-storey multi-bay structure, b) assessing the seismic displacement demand of the infilled RC frame under the two directions loadings.

\section{Acknowledgements}

This work is financially supported by the NSFC (51078117), Key Scientific and Technological Project in Heilongjiang Province (GB06C102), and HIT Fund for Distinguished Young Scholars (QJKY985016).

\section{References}

1 McDowell E L, McKee K E, Sevin E, Arching Action Theory of Masonry Walls, In: Proceedings of the American Society of Civil Engineers, Vol. 82, 1956, pp. 1-18.

2 Angel R, Abrams D P, Shapiro D, Uzarski J, Webster M, Behavior of Reinforced Concrete Frames with Masonry Infills, Department of Civil Engineering, University of Illinois, Urbana-Champaign, IL, USA, (1994).

3 Flanagan R D, Bennett R M, Bidirectional Behavior of Structural Clay Tile Infilled Frames, Journal of structural engineering, 125(3), (1999), 236-244, DOI 10.1061/(ASCE)0733-9445(1999)125:3(236)
4 Liauw T C, Kwan K H, Nonlinear Analysis of Multistory Infilled Frames, Proceedings of the Institution of Civil Engineers, In:, Vol. 73, 1982, pp. 441454.

5 Lotfi H R, Shing P B, An Appraisal of Smeared Crack Models for Masonry Shear Wall Analysis, Computers and Structures, 41(3), (1991), 413-425, DOI 10.1016/0045-7949(91)90134-8

6 Lotfi H R, Shing P B, Interface Model Applied to Fracture of Masonry Structures, Journal of Structural Engineering, ASCE, 120(1), (1994), 63-80, DOI 10.1061/(ASCE)0733-9445(1994)120:1(63)

7 Lourenco P B, Computational Strategies for Masonry Structures, Delf University Press; Netherlands, 1996.

8 Lourenco P B, Rots J G, On the Use of Micro-Models for the Analysis of Masonry Shear-Walls, The Second International Symposium on Computer Methods in Structural Masonry, In:; Swansea, UK, April 1993, pp. 14-26.

9 Lourenco P B, Rots J G, Understanding the Behavior of Shear Walls, A Numerical Review, The 10th International Brick and Block Masonry Conference, In:; Calgary, Canada, 1994, pp. 11-20.

10 Haris I, Hortobágyi Z, Different FEM Models of Reinforced Concrete Frames Stiffened by Infill Masonry for Lateral Loads, Periodica Polytechnica Civil Engineering, 56(1), (2012), 25-34, DOI 10.3311/pp.ci.2012-1.03

11 Seah C K, A Universal Approach for the Analysis and Design of Masonry Infilled Frame Structures, PhD Thesis, The University of New Brunswick, Canada, (1998).

12 Mehrabi A B, Behavior of Masonry-Infilled Reinforced Concrete Frames Subjected to Lateral Loadings, (1994). PhD Thesis, University of Colorado, Colorado, USA.

13 Stavridis A, Shing P B, Finite-Element Modeling of Nonlinear Behavior of Masonry-Infilled RC Frames, Journal of Structural Engineering, ASCE, 136(3), (2010), 285-296, DOI 10.1061/(ASCE)ST.1943-541X.116

14 ABAQUS User's Manual, Version 6.11; Pawtucket, RI, 2011.

15 Code for design of concrete structure (GB50010-2010). In Chinese.

16 Zhai C, Kong J, Wang X, A Finite Element Model for Simulating Out-of-plane Behavior of Masonry Infilled RC Frames, Applied Mechanics and Materials, 166-169, (2012), 849-852, DOI 10.4028/www.scientific.net/AMM.166-169.849

17 Kong J, Zhai C, Li S, Xie L, Study on In-plane Seismic Performance of Solid Masonry-Infilled RC Frames, China Civil Engineering Journal, 45, (2012), 137-141.

18 Fardis M N, Panagiotakos T B, Seismic Design and Response of Bare and Masonry-Infilled Reinforced Concrete Buildings. Part II: Infilled Structures, Journal of Earthquake Engineering, 1, (1997), 475-503, DOI 10.1080/13632469708962375

19 Karayannis C G, Kakaletsis D J, Favvata M J, Behavior of Bare and Masonry Infilled R/C Frames under Cyclic Loading: Experiments and Analysis, Earthquake Resistant Engineering Structures, 81, (2005), 429-438.

20 Dolsek M, Fajfar P, Inelastic Spectra for Infilled Reinforced Concrete Frames, Earthquake Engineering and Structural Dynamics, 33, (2004), 1395 1416, DOI 10.1002/eqe.410

21 Dolšek M, Fajfar P, The Effect of Masonry Infills on the Seismic Response of A Four Storey Reinforced Concrete Frame-A Probabilistic Assessment, Engineering Structures, 30, (2008), 3186-3192, DOI 10.1016/j.engstruct.2008.01.001

22 Rodrigues H, Varum H, Costa A, A non-linear masonry infill macro-model to represent the global behaviour of buildings under cyclic loading, International Journal of Mechanics and Materials in Design, 4, (2008), 123-135, DOI 10.1007/s10999-008-9070-6

23 Valiasis T N, Stylianidis K C, Penelis G G, Hysteretic Model for Weak Brick Masonry Infills in R/C Frames under Lateral Reversals, European Earthquake Engineering, 4(3-9), (1993). 